\title{
Symptoms and quality of life from patients undergoing hemodialysis in Switzerland
}

\author{
Philippe Delmas*1 ${ }^{*}$, Christine Cohen ${ }^{1}$, Marie-Chantal Loiselle ${ }^{2}$, Matteo Antonini ${ }^{1}$, Jerome Pasquier ${ }^{3}$, Michel Burnier ${ }^{4}$ \\ ${ }^{1}$ La Source, School of Nursing, University of Applied Sciences and Arts Western Switzerland, Lausanne, Switzerland \\ ${ }^{2}$ School of Nursing, Faculty of Medecine and Health Sciences, University of Sherbrooke, Sherbrooke, Québec, Canada \\ ${ }^{3}$ Institute of Social and Preventive Medicine, Vaud University Hospital - CHUV, Lausanne, Switzerland \\ ${ }^{4}$ Service of Nephrology, Department of Medicine, Vaud University Hospital - CHUV, Lausanne, Switzerland
}

Received: October 23, 2017

DOI: $10.5430 /$ cns.v6n2p63
Accepted: December 7, 2017

Online Published: December 20, 2017

\begin{abstract}
Background: Dialysis patients experience multiple symptoms impairing their quality of life. A relationship seems to exist between the cultural context and the burden of symptoms. In this study, the prevalence and severity of 30 symptoms and their relationship with quality of life among hemodialysis patients in Switzerland is explored.

Methods: A cross-sectional correlation design was used with a convenience sample of 119 patients from five dialysis units. Presence and severity of symptoms were assessed with the Dialysis Symptom Index and quality of life with the WHOQOL-Bref questionnaire. Multivariate linear regressions were used to examine the relationship between the prevalence and severity of symptoms, respectively, and quality of life. $T$-tests and Fisher's tests were used for the international comparisons.

Results: On average, patients reported 10 symptoms and often rated these as "somewhat bothersome". The most frequent were: lack of energy, dry skin, trouble falling asleep, trouble staying asleep, and muscle cramps. Average symptoms prevalence and severity levels were both observed to decrease patients' quality of life, items related to physical health and psychological state having the greatest impact. Prevalence and severity of psychological symptoms and prevalence of sex-related symptoms seem to be influenced by patients' cultural context.

Conclusions: These results demonstrate that patients on chronic hemodialysis present several symptoms that affect their quality of life. Healthcare professionals should develop strategies to identify more properly these symptoms, especially sex-related and psychological symptoms.
\end{abstract}

Key Words: Symptom burden, Quality of life, Hemodialysis, Theory of symptom management

\section{INTRODUCTION}

During the last decades, chronic diseases have supplanted communicable diseases as the first cause of mortality and morbidity in the population. ${ }^{[1]}$ Chronic kidney disease (CKD) is one of the chronic diseases that has grown rapidly, most often in connection with the degradation of kidney function secondary to another chronic condition, such as diabetes or hypertension ${ }^{[1]}$ but also due to the ageing of the population. According to the Global Burden of Disease Study, ${ }^{[2]}$ CKD ranked $18^{\text {th }}$ on the list of causes of global deaths in 2010 (16.3 per 100,000 deaths annually) and has now become a serious public health issue. ${ }^{[3]}$ Moreover, patients with CKD inevitably progress, over the medium to long term, towards end-stage renal disease (ESRD), which necessitates

\footnotetext{
*Correspondence: Philippe Delmas; Email: p.delmas@ecolelasource.ch; Address: La Source, School of Nursing, University of Applied Sciences and Arts Western Switzerland, Lausanne, Switzerland.
} 
long-term renal replacement therapy, the most common of which is hemodialysis (HD). ${ }^{[4]}$ Switzerland has not been spared from the phenomenon: 350,000 of its inhabitants live with the disease, 30,000 of which with a severe form of the disease. ${ }^{[5]}$ Consequently, CKD patients necessitating HD treatment are on track the way to become a large vulnerable population with complex healthcare needs.

Though extra-renal blood purification treatment such as HD does prolong the life of ESRD patients, it carries numerous constraints and can generate major complications. ${ }^{[6]}$ In this regard, authors ${ }^{[7-22]}$ have pointed out that patients on chronic HD experience a multitude of symptoms, both physical and psychological, owing primarily to the trajectory of the kidney disease, to the different treatments received, and to their side effects. In a review of the recent literature on the topic, Almutary et al. ${ }^{[8]}$ mentioned that the mean number of symptoms per HD patient ranged from 6 to 20 across studies and that the main symptoms reported by CKD patients, including those on HD, were fatigue or lack of energy $(81 \%)$, feeling drowsy (75\%), pain (65\%), pruritus $(61 \%)$ and dry skin $(57 \%)$. While the prevalence of physical symptoms is considerable, HD patients also experience symptoms of a psychological order, such as feeling sad, feeling irritable, and feeling nervous. ${ }^{[7,14,17,23]}$ According to Humphreys et al., ${ }^{[24]}$ any bothersome symptom not managed by the patient or healthcare professionals can have negative repercussions on patient health. Consequently, it is not surprising that studies ${ }^{[7,16,17,23]}$ have found increased symptom burden to be closely related to change in quality of life (QoL) among HD patients and QoL to be a predictor of mortality in this population. ${ }^{[25]}$

Ten years ago, Weisbord ${ }^{[23]}$ bemoaned the scant research geared to explore the prevalence and severity of selfperceived symptoms among HD patients and to evaluate their effect on QoL and depression. Almutary et al. ${ }^{[8]}$ reiterated this point more recently, underscoring the need to acquire a better understanding of symptom burden. In addition, Weisbord et al. ${ }^{[26]}$ found there were cultural differences regarding prevalence and severity of self-perceived symptoms among HD patients around the world. All of this suggests that the symptomatology of HD patients should be explored systematically in light of the cultural context in order not only to enrich our understanding of this phenomenon but also subsequently to propose tailored interventions. In Switzerland, despite the growing number of HD patients, no study has ever specifically explored the symptomatology of this population. Furthermore, Almutary et al ${ }^{[8]}$ pointed out that research on the subject often lacked a theoretical basis, which constituted a shortcoming in terms of the choice of variables investigated and the proposed relationship between them. Against this background and drawing on Humphreys' theory of symptom management, ${ }^{[24]}$ we undertook a study with a twofold objective: 1) to measure the prevalence and severity of physical and emotional symptoms among HD patients in Switzerland; and 2) to examine the relationship between symptom prevalence and severity and patient QoL.

\section{THEORETICAL FRAMEWORK}

The UCSF School of Nursing Symptom Management Model $^{[24]}$ provided the theoretical framework for the study. Effective symptom management involves taking into consideration three interrelated dimensions: symptom experience, symptom management strategies, and outcomes. A symptom was defined as a subjective experience reflecting a change in state of health impacting well-being, especially among people living with a chronic disease. ${ }^{[24]}$ The notion of symptom experience allowed researchers to identify the symptoms that HD patients perceived and to determine their frequency and severity. Humphreys et al. ${ }^{[24]}$ specified that symptoms unsupported by health professionals still had a major impact on patients, their family and the healthcare system. According to these researchers, this middle-range theory can help direct research on symptom assessment, strategies used by people to manage symptoms, and how symptoms affect their health status. This theory is used to define the relationship between the variables under study.

\section{METHOD}

\subsection{Study design}

A cross-sectional correlational design ${ }^{[27]}$ was used to describe two dimensions of HD patient symptom experience prevalence and severity - and subsequently, to investigate the relationship between symptom experience and patient QoL.

\subsection{Participants and setting}

A convenience sample was recruited in five dialysis centers in the Canton of Vaud (French-speaking part of Switzerland) during routine weekday dialysis sessions. To be included in the study, participants had to meet the following criteria: 1) age 18 years or older; 2) under active treatment for at least six months; 3) fluent in written and spoken French; and 4) able to provide free and informed consent. Patients with diagnosed dementia or in a critical condition were excluded, as were people with a weak command of French. Patients who consented to participate in the study completed a structured self-report questionnaire. A research assistant was on site at the time to assist them, if needed (e.g., explain certain questions or even read out all the items of the questionnaire). The questionnaire took about 30 minutes to complete on average and was collected at the end of the dialysis session. 


\subsection{Measures}

\subsubsection{Sociodemographic and clinical data}

Data were collected on sociodemographic dimensions, including age, sex, marital status, employment situation, children, and income, and on clinical concerns, including tobacco and alcohol use, years on dialysis and presence of comorbid conditions. The clinical data were gathered from hospital records. Also collected from the records were a set of biological markers (albumin, hemoglobin, phosphate, calcium, parathyroid hormone) and an indicator of dialysis adequacy $(\mathrm{kt} / \mathrm{v})$. The core elements indicated by Boini et al. ${ }^{[28]}$ in their longitudinal study of QoL among 1,000 French CKD patients were used as the basis of the questionnaire in our study. This questionnaire had already been successfully used in a past study of HD patients living in Switzerland. ${ }^{[29]}$

\subsubsection{Symptoms}

Prevalence and severity of physical and emotional symptoms were assessed with the 30-item Dialysis Symptom Index $\left(\mathrm{DSI}^{[30]}\right)$. Respondents were asked to indicate whether they experienced any of 30 symptoms in the past 7 days. Then, for each patient, a symptom burden score ranging from 0 to 30 was calculated summing the reported symptoms scores. ${ }^{[31]}$ In addition, severity was measured for each reported symptom following the procedure proposed by Weisbord. ${ }^{[30-32]}$ Specifically, patients were asked to rate each reported symptom on a 5-point Likert scale from 1 (not at all bothersome) to 5 (bothers very much). Symptoms not present were rated 0 in terms of severity. ${ }^{[31]}$ Then, an overall symptom severity score ranging from 0 to 150 was calculated by summing the individual severity ratings. ${ }^{[31]}$ The English version of the DSI has been tested in different national contexts and has obtained satisfactory scores on a number of psychometric properties. ${ }^{[26,30-32]}$ For the purposes of our study, the DSI was translated into French following the transcultural validation method proposed by Vallerand. ${ }^{[33]}$ Psychometrics tests has demonstrated good psychometric properties of the French version. The test-retest reliability method was used and results showed a percent agreement of $61.9 \%$ to $95.2 \%$, with most of the symptoms (24/30) obtaining a percent agreement equal to or greater than $80 \%$. Average kappa statistics was $0.53(S D=0.21)$, a value that is larger than the threshold for moderate agreement, i.e. 0.4. ${ }^{[34]}$ Finally, the items obtained a Cronbach's $\alpha$ of 0.83 regarding symptom prevalence and of 0.89 regarding symptom severity. On the whole, the tests indicated that the fidelity of the French version of the DSI was more than satisfactory. ${ }^{[35]}$

\subsubsection{Quality of life (QoL)}

Patient self-perceived QoL was assessed with the Frenchlanguage version of the WHOQOL-BREF, ${ }^{[36]}$ an abridged version of the 100-item World Health Organization Quality of Life instrument. The WHOQOL-BREF comprises 26 items, two of which serve to explore overall QoL and general health. The other 24 items fall under four domains: physical health (seven items), psychological state (six items), social relationships (three items), and environmental conditions (eight items). All were rated on a 5-point scale from 1 to 5, with higher scores indicating better QoL. Then, raw scores were normalized on a $0-100$ scale. The WHOQOL-BREF questionnaire has been shown to possess good discriminant and content validity, as well as good test-retest reliability and high internal consistency. ${ }^{[37]}$ The French language translation was validated ${ }^{[36]}$ on French-speaking patients with neuromuscular disorders and has been proven to possess satisfactory psychometric properties (Cronbach's $\alpha>0.65$ for each dimension and good acceptability by population with less than 5\% non-response). The instrument had already been successfully used in a previous study with French-speaking HD patients. ${ }^{[29]}$

\subsection{Data analysis}

First, quantitative variables were described using the following statistics: minimum, maximum, mean, standard deviation, median, and interquartile range (IQR). Qualitative variables were described using frequency tables with counts and percentages. Second, a set of Kruskal-Wallis tests was run to describe differences in the distribution of symptom prevalence and severity across sociodemographic and clinical groups. Third, the Pearson correlation coefficient and multivariate linear regression analysis were used to examine the relationship between symptom prevalence and severity, respectively, and patient QoL (adjusting for sociodemographic, clinical and biological characteristics). Finally, to compare the distribution of symptom prevalence and severity found in our study with similar metrics obtained for Italian and American patients, ${ }^{[26]}$ a set of $t$-tests and Fisher tests were employed. The statistical significance level ( $p$-value) was set at $5 \%$ or less throughout. All statistical analyses were run using the R-3.3.3 software package.

\subsection{Ethical consideration}

All HD patients were handed a document explaining the purpose of the study and the procedures used to ensure anonymity. Patients could refuse to participate and were free to withdraw from the research at any time without prejudice to their medical support. Those who agreed to participate after sufficient reflection were asked to sign a consent form, which was later forwarded to the researchers. The study was approved by the Human Research Ethics Review Board of the Canton of Vaud (Switzerland). 
Table 1. Sociodemographic and clinical characteristics of study patients

\begin{tabular}{|c|c|c|c|}
\hline \multirow{2}{*}{ Sociodemographic, clinical and biological characteristics } & \multicolumn{3}{|c|}{ Study group $(\mathrm{N}=119)$} \\
\hline & Mean $(S D)$ & n & $\%$ \\
\hline Age (in years) & $67.1(14.2)$ & & \\
\hline \multicolumn{4}{|l|}{ Sex } \\
\hline - Female & & 43 & 36.1 \\
\hline - Male & & 76 & 63.9 \\
\hline \multicolumn{4}{|l|}{ Marital status } \\
\hline - Single & & 12 & 10.1 \\
\hline - Married & & 63 & 52.9 \\
\hline - Separated & & 18 & 15.1 \\
\hline - Widowed & & 21 & 17.6 \\
\hline - Living common law & & 5 & 4.2 \\
\hline \multicolumn{4}{|l|}{ Employment status } \\
\hline - Active & & 15 & 12.6 \\
\hline - Inactive & & 31 & 26.1 \\
\hline - Retired & & 73 & 61.3 \\
\hline Children (yes) & & 89 & 74.8 \\
\hline \multicolumn{4}{|l|}{ Annual income (in $\mathrm{CHF})_{(1 \text { missing value) }}$} \\
\hline • 32,579 or less & & 51 & 43.2 \\
\hline - 32,580 to 43,132 & & 35 & 29.7 \\
\hline - 43,133 to 54,785 & & 20 & 16.9 \\
\hline - 54,786 to 71,616 & & 6 & 5.1 \\
\hline - 71,617 or more & & 6 & 5.1 \\
\hline Months on hemodialysis & $46.6(51.3)$ & & \\
\hline \multicolumn{4}{|l|}{ Tobacco } \\
\hline - Former smoker & & 53 & 44.5 \\
\hline - Smoker & & 23 & 19.3 \\
\hline - Non-smoker & & 43 & 36.1 \\
\hline \multicolumn{4}{|l|}{ Alcohol } \\
\hline - None & & 61 & 51.3 \\
\hline - Fewer than two standard units ${ }^{*}$ per day & & 55 & 46.2 \\
\hline - More than two standard units ${ }^{*}$ per day & & 3 & 2.5 \\
\hline On transplant waiting list $(1$ missing value) & & 36 & 30.5 \\
\hline Heart failure & & 38 & 31.9 \\
\hline Hypertension & & 69 & 58.0 \\
\hline Cardiac arrhythmia & & 25 & 21.0 \\
\hline Diabetes $_{(1 \text { missing value) }}$ & & 47 & 39.8 \\
\hline Peripheral vascular disease & & 11 & 9.2 \\
\hline Chronic respiratory insufficiency & & 12 & 10.1 \\
\hline Tumor & & 7 & 5.9 \\
\hline Hepatitis & & 4 & 3.4 \\
\hline Amputation & & 7 & 5.9 \\
\hline Hemiplegia & & 2 & 1.7 \\
\hline Blindness & & 8 & 6.7 \\
\hline Albumin $(\mathrm{g} / \mathrm{dL}, \min -\max : 35-52)^{*}$ & $3.8(0.7)$ & & \\
\hline Hemoglobin (g/dL, min-max: $12-16)^{*}$ & $11.2(1.3)$ & & \\
\hline Phosphate (mg/dL, min-max: $0.8-1.4)^{*}$ & $1.3(0.5)$ & & \\
\hline Calcium $(\mathrm{mg} / \mathrm{dL}, \min -\max : 8.4-10.0)^{*}$ & $9.2(0.8)$ & & \\
\hline Parathyroid hormone $(\mathrm{pg} / \mathrm{mL} \text {, min-max: } 150-300)^{*}{ }_{(1 \text { missing value })}$ & $319.7(280.1)$ & & \\
\hline $\mathrm{kt} / \mathrm{v}$ (min-max: $0.94-2.29)^{* *}$ (1 missing value) & $1.6(0.5)$ & & \\
\hline
\end{tabular}

Note. ${ }^{*}$ Norms of Vaud (Switzerland); ${ }^{* *}$ According to KDIGO 2012 Clinical Practice Guidelines for the Evaluation and Management of Chronic Kidney Disease (National Kidney Foundation, 2013)

\section{Results}

\subsection{Sample characteristics}

From January 2013 to September 2013, 119 HD patients were enrolled in the study. Their sociodemographic characteristics are shown in Table 1. Nearly two-thirds of participants were male and the mean age of sample was pretty high (67 years). Three-quarters of the pooled sample had children and slightly more than half was married. The vast majority $(87.4 \%)$ were retired or reported no gainful activity. This explained the low income reported: about $90 \%$ earned less than 54,785 CHF, well below the average annual income in Switzerland of 85,740 CHF in 2013. ${ }^{[38]}$ Nearly two-thirds of the patients were smokers or former smokers and almost half consumed alcohol. However, only $2.5 \%$ engaged in risky drinking behaviors (more than two standard units per day) based on the Canadian low-risk drinking guidelines ${ }^{[39]}$ often applied in Switzerland. ${ }^{[40]}$ Patients had been on hemodialysis for 47 months on average and $31 \%$ were on the transplant 
waiting list. Regarding medical history, the most present comorbidities was hypertension, diabetes mellitus, and heart failure. Mean values for all biological markers fell within the non-problematic zone, except for hemoglobin, which was slightly below the minimum level, and for parathyroid hormone, which topped the maximum level but varied widely across the sample.

Table 2. Prevalence and severity of symptoms $(\mathrm{N}=119)$

\begin{tabular}{lll}
\hline Symptoms & $\begin{array}{l}\text { Prevalence } \\
\text { n }(\%)^{*}\end{array}$ & $\begin{array}{l}\text { Severity } \\
\text { Mean }(\boldsymbol{S D})^{* * *}\end{array}$ \\
\hline Feeling tired or lack of energy & $86(72.3 \%)$ & $3.4(1.1)$ \\
Dry skin & $72(60.5 \%)$ & $3.1(1.2)$ \\
Trouble falling asleep & $62(52.1 \%)$ & $3.6(1.1)$ \\
Muscle cramps & $60(50.4 \%)$ & $3.2(1.2)$ \\
Trouble staying asleep & $60(50.4 \%)$ & $3.4(1.2)$ \\
Decreased interest in sex & $57(47.9 \%)$ & $4.1(1.1)$ \\
Dry mouth & $56(47.1 \%)$ & $3.2(1.3)$ \\
Bone or joint pain & $56(47.1 \%)$ & $3.3(1.1)$ \\
Itching & $56(47.1 \%)$ & $3.1(1.7)$ \\
Difficulty becoming sexually aroused & $54(45.4 \%)$ & $4.1(1.1)$ \\
Shortness of breath & $50(42.0 \%)$ & $2.9(1.0)$ \\
Feeling anxious & $45(37.8 \%)$ & $3.3(1.1)$ \\
Feeling nervous & $43(36.1 \%)$ & $2.8(1.1)$ \\
Worrying & $42(35.3 \%)$ & $3.3(1.1)$ \\
Numbness or tingling in feet & $40(33.6 \%)$ & $2.8(1.1)$ \\
Difficulty concentrating & $40(33.6 \%)$ & $2.7(1.0)$ \\
Muscle soreness & $39(32.8 \%)$ & $2.8(1.0)$ \\
Feeling irritable & $39(32.8 \%)$ & $2.7(0.9)$ \\
Decreased appetite & $37(31.1 \%)$ & $2.9(1.6)$ \\
Cough & $37(31.1 \%)$ & $2.7(1.1)$ \\
Feeling sad & $36(30.3 \%)$ & $3.3(1.3)$ \\
Restless legs or difficulty keeping legs still & $34(28.6 \%)$ & $3.0(1.0)$ \\
Constipation & $30(25.2 \%)$ & $3.3(1.4)$ \\
Headache & $30(25.2 \%)$ & $2.8(1.0)$ \\
Lightheadedness or dizziness & $27(22.7 \%)$ & $2.7(1.0)$ \\
Swelling in legs & $25(21.0 \%)$ & $2.8(1.1)$ \\
Diarrhea & $21(17.6 \%)$ & $3.0(1.1)$ \\
Nausea & $20(16.8 \%)$ & $3.1(1.4)$ \\
Vomiting & $15(12.6 \%)$ & $2.8(1.1)$ \\
Chest pain & $14(11.8 \%)$ & $3.0(1.2)$ \\
GLOBAL sCORE & 10 & $32(\mathrm{IQR}:$ \\
& $(\mathrm{IQR}: 6-14)$ & $16.5-45.5) * * *$ \\
\hline Note. & & \\
& &
\end{tabular}

Note. ${ }^{*}$ Number of patients that reported symptom, percentage calculated on total $(\mathrm{N}=119) ;{ }^{* * *}$ Based on a Likert scale from 1 "not at all bothersome" to 5 "bothers very much..."; *** Median overall symptom severity score; Absence of symptom scored 0 in terms of severity

\subsection{Symptom experience}

For the 119 participants, the median number of symptoms reported was 10 (IQR: 6-14). As shown in Table 2, five symptoms were reported by at least $50 \%$ of the patients: feeling tired or lack of energy, dry skin, trouble falling asleep, trouble staying asleep, and muscle cramps. Regarding symptom severity, two symptoms rated above 4 (high) and 13 rated 3 to 4 (moderate). The most severe symptoms were the following: decreased interest in sex, difficulty becoming sexually aroused, trouble falling asleep, feeling tired or lack of energy, trouble staying asleep. The median global score for symptom severity was 32 (IQR: 16.5-45.5). No sociode- mographic characteristics or biological markers were related to symptom prevalence or severity $(p>.05)$. Where clinical variables are concerned, hypertension, hepatitis, and peripheral vascular disease increased both prevalence and severity of symptoms (respectively, $p=.002$ and $p=.002, p=.041$ and $p=.013, p=.048$ and $p=.030)$. Presence of a tumor increased symptom prevalence $(p=.042)$ but not severity. Surprisingly, being on the transplant waiting list was not related to prevalence or severity of symptoms. Finally, a principal component factor analysis of symptoms reported on the French version of the DSI revealed no symptom cluster in our sample.

Table 3. Regression models linking symptom prevalence and severity, respectively, and QoL

\begin{tabular}{|c|c|c|c|c|}
\hline & Overall $\beta$ & & Overall $\beta$ & \\
\hline \multicolumn{5}{|l|}{ QoL: Overall } \\
\hline Symptom prevalence & -1.76 & $*$ & --- & \multirow[b]{2}{*}{ * } \\
\hline Symptom severity & --- & & -0.47 & \\
\hline \multicolumn{5}{|l|}{ QoL: Physical Health } \\
\hline Symptom prevalence & -1.63 & * & --- & \multirow[b]{2}{*}{ * } \\
\hline Symptom severity & --- & & -0.48 & \\
\hline \multicolumn{5}{|c|}{ QoL: Psychological State } \\
\hline Symptom prevalence & -0.97 & $*$ & --- & \multirow[b]{2}{*}{ * } \\
\hline Symptom severity & --- & & -0.27 & \\
\hline \multicolumn{5}{|c|}{ QoL: Social Relationships } \\
\hline Symptom prevalence & -0.57 & $\dagger$ & --- & \multirow[b]{2}{*}{ * } \\
\hline Symptom severity & --- & & -0.17 & \\
\hline \multicolumn{5}{|c|}{ QoL: Environmental Conditions } \\
\hline Symptom prevalence & -0.36 & & --- & \\
\hline Symptom severity & --- & & -0.08 & \\
\hline
\end{tabular}

Note. Controls (for all models): variables listed in Table 1, height and weight ( $\beta$ values not shown); ${ }^{*} p<.05 ;{ }^{\dagger}$ marginally significant $(p=.06)$

\subsection{Correlation between symptoms and QoL}

A significant negative Pearson correlation was observed between global scores for symptom prevalence and severity, respectively, and patient QoL $(-0.36$ and $-0.39, p<.001$ in both cases). Similar results were obtained for each of the components of patients' QoL (physical health, psychological state, social relationships, and environmental conditions). Pearson correlation coefficients ranged from -0.61 (physical health and symptom severity) to - 0.20 (environmental conditions and symptom prevalence) and were all statistically significant. To determine whether the results were robust to the inclusion of confounding variables, ten regression models (see Table 3) were run to describe the net relationship between variation in symptom prevalence and severity, respectively, and QoL. The results of these models showed that an increment in symptom prevalence was significantly associated with a decrement in QoL. Considering a scale 
ranging from 0 to 100 , where 0 represents the worst possible QoL and 100 the best, the regression model showed decrements ranging from 1.63 points for physical health to 0.36 for environmental conditions, and reaching 1.76 for overall QoL. All the relationships were statistically significant except for those regarding environmental conditions. As for symptom severity, decrements ranged from 0.48 point for physical health to 0.08 for environmental conditions, and reached 0.47 for overall QoL. Again, all relationships were statistically significant $(p<.05)$ except for those regarding environmental conditions.

\section{Discussion}

Our results evidenced a high prevalence of physical and psychological symptoms among HD patients living in the French-speaking part of Switzerland. The patients in our study reported an average of 10 symptoms, which is in line with several other studies where the average number of symptoms reported ranged from 6 to $20 .{ }^{[8]}$ More specifically, the comparison with our results against those obtained by Weisbord et al., ${ }^{[26]}$ using identical instruments on Italian and American HD patients, shows that the average number of symptoms reported by Swiss patients was slightly greater than the average number reported by American patients (9), but less than the average number reported by Italian patients (14). Even if the general levels are consistent and remain high, context-related differences are evident and would need further investigation. HD patients seem to experience more symptoms than do people at an earlier stage of the illness or with other pathologies, notably cancer. ${ }^{[14,21]}$ More specifically, "feeling tired or lack of energy" was the most commonly reported symptom, reaching a prevalence of $72 \%$. Almutary et al. ${ }^{[8]}$ found this symptom to be the most frequently reported, with prevalence ranging from $49 \%$ to $92 \%$ across studies. Similarly, Weisbord et al. ${ }^{[26]}$ found analogous results with a sample of Italian and American patients: "feeling tired or lack of energy" affected $82 \%$ of the former and $68 \%$ of the latter. Four other symptoms were reported by more than $50 \%$ of our patients: dry skin $(60.5 \%)$, trouble falling asleep $(52.1 \%)$, trouble staying asleep $(50.4 \%)$, and muscle cramps $(50.4 \%)$. The strong presence of these symptoms is in line with the findings reported by Weisbord et al. ${ }^{[26]}$ and Almutary et al. ${ }^{[8]}$ However, the prevalence of other symptoms differed in our study from the percentages reported in the just quoted studies. In our comparison with the results reported by Weisbord et al., ${ }^{[26]}$ the same pattern emerged for 10 symptoms (bone or joint pain, worrying, difficulty becoming sexually aroused, feeling sad, feeling anxious, decreased interest in sex, feeling irritable, constipation, feeling nervous, difficulty concentrating), namely, the highest prevalence was observed among Italian patients, the lowest among American patients, and an intermediate level among Swiss patients. Sex-related symptoms were prominent. Indeed, $48 \%$ of our sample reported decreased interest in sex and $45 \%$ reported increased difficulty becoming sexually aroused. In the Weisbord et al. ${ }^{[26]}$ study, fewer than one-quarter of the American patients reported sex-related issues, whereas these were the symptoms most reported by the Italian patients (both at $82 \%$ ). All these results suggest that cultural context could be a key factor in the prevalence of certain symptoms.

Regarding symptom severity, a simple comparison of symptom severity showed substantial differences across the national patient groups. The average score for our patients was 32 (IQR: 16-45), greater than the scores reported by Weisbord et al., ${ }^{[23,26,31]}$ which reached 22 and 25 . This difference rested on the fact that 18 of 30 symptoms in our study scored 3 or higher (i.e., moderate severity), compared with only 12 and 14, respectively, for the two groups in the Weisbord et al. ${ }^{[26]}$ study. As was the case in Weisbord et al. ${ }^{[31]}$ and in Danquah et al., ${ }^{[10]}$ many of the most prevalent symptoms in our study were also among the most severe, which might explain the high average severity score we obtained. For example, this was true for the severity of sleep issues, which was in line with previous research that described them as common among HD patients, strictly connected to HD treatment and having a major impact on QoL. ${ }^{[41]}$ Many of these symptoms are undertreated, often owing to a general lack of proper treatment for HD symptoms. ${ }^{[42]}$ In particular, even if pain represents a constant concern among health professionals, strategies to reduce pain in HD patients still seem wanting. ${ }^{[42,43]}$ In part this is due to organizational uncertainty about who, the nurse or the physician, is responsible for treating symptoms. ${ }^{[44]}$ Further to these results, healthcare professionals should assess presence of pain in HD patients systematically and propose pharmacological and non-pharmacological solutions to remedy the situation.

If we consider the findings on HD patient symptom prevalence and severity together, context emerges as a key factor. Sex-related symptoms, in particular, follow a particular pattern. Their prevalence is high in Italy, low in the United States, and at an intermediate level in Switzerland. However, unlike other symptoms that follow this pattern, their severity is very high in all three contexts: 4.1 in Switzerland, 4.0 in Italy, and 3.0-4.0 in the United States. This result is in line with other studies that found sex-related symptoms to be a major issue for HD patients ${ }^{[45]}$ regardless of cultural differences. ${ }^{[46]}$ Despite the solid literature on the subject, until recently sex-related symptoms have remained in the shadows because patients considered them part of the natural aging 
process $^{[47]}$ and healthcare professionals tended to underestimate them on account of their "non-lethal nature". $[47,48]$ Moreover, both healthcare professionals and patients are at times embarrassed to talk about these issues ${ }^{[47]}$ despite the desire for information and, if needed, treatment. The literature suggests that the taboo surrounding sexual practices, in general, and patient sexuality, in particular, are still problematic issues for both healthcare professionals and researchers. How HD facilities are organized may contribute to maintain this taboo: they often have an open-space layout that complicates communication between patients and healthcare professionals or researchers. This may be why Weisbord et al. have noted a clear reluctance among patients to answer questions about sex-related matters ${ }^{[26]}$ and why the results reported by Coelho-Marques et al. are likely underestimated. ${ }^{[49]}$ Generally speaking, it would not be unreasonable to assume that a large part of the measures regarding sexrelated symptoms are underestimated. Given the above, many researchers ${ }^{[45,48,50]}$ have come out in favor of paying greater attention to sex-related issues among HD patients, especially women's pathologies and non-pharmacological treatment, two issues largely unexplored in this field of study. ${ }^{[50]}$

In addition to sex-related symptoms, a set of psychological symptoms, including "worrying", "feeling anxious", "feeling irritable", "feeling nervous", and "feeling sad", rated high among Italian patients, low among American patients, and inbetween among Swiss patients. This is true in terms of both prevalence and severity, which further emphasizes the role of context in this regard. Researchers have noted the importance of context empirically in the past but without detailing what lies at the root of the differences. ${ }^{[26,51,52]}$ The relevance of context is described in Humphreys' theory of symptom management. ${ }^{[24,53]}$ Even if context is not at the center of the theory, it can be broken down into three dimensions: cultural, organizational, and structural. ${ }^{[24,53]}$ First, the cultural dimension covers behavioral models and semantic nuances. The influence of this dimension is interpreted from a constructivist perspective ${ }^{[54,55]}$ that considers every aspect of an individual's life as an experience to be interpreted in terms of cultural models. From this perspective, illness and symptoms, too, are experiences that are "socially constructed"[55] [p.70] and that are influenced by social rules that prescribe how to "live" and communicate the experience. Moreover, the medical approach that identifies this change as a symptom is more pervasive in some cultures than in others ${ }^{[56]}$ and this influences how patients identify and, in turn, report symptoms. These cultural differences are all the more pronounced when it comes to psychological symptoms (e.g., worrying, feeling anxious, feeling irritable), which are entirely self-reported. Linguistic interactions, for their part, are not merely a means for spreading cultural models, they add a further element of differentiation. However rigorous the method used to translate the original English scale, equivalent terms can have small semantic nuances and connotations that impact how symptoms are perceived and reported. Though the Italian and French translations of the DSI scale are technically impeccable, semantic differences might remain and could have influenced results. Second, the organizational dimension refers to the fact that HD facilities are organized differently in terms of both procedures and the healthcare professional delivering treatment (i.e., dialysis technician in the United States, nurse in Switzerland and Italy). These differences can influence the easiness that patients feel relating to healthcare professionals and, consequently, the way they perceive and report their symptoms. Third, the structural dimension refers to differences across the national healthcare systems. Rothgang et al. ${ }^{[57]}$ developed a typology to classify these systems based on who controls service regulation, funding, and delivery. Accordingly, the Unites States is classified as a private healthcare system ${ }^{[58]}$ that rests on non-compulsory private health insurance. Despite the high public cost of the system, ${ }^{[59]}$ funding is mainly indirect and the system is not universally accessible. On the other hand, Italy is classified as a system based on a national health insurance ${ }^{[58]}$ funded and regulated by the state and provided by both public and private facilities. The system is universally accessible and costs are state regulated. Switzerland is classified as a system based on a social health insurance. ${ }^{[58]}$ This system rests on compulsory private insurance strictly regulated by public authorities. Our results and those reported by Weisbord et al. ${ }^{[26]}$ suggest that the more a healthcare system is tax-based or publicly funded, the less HD patients worry about the cost of treatment and, consequently, the less likely they are to minimize presence and severity of symptoms. Clearly, further research is required in this regard in order to gain a better grasp of the issue.

Also, our results show that patient QoL decreases systematically when symptoms worsen and even more so when new symptoms appear. This relationship was weak, however, as observed in previous research. ${ }^{[16,60]}$ We found that when an existing symptom worsens, QoL decreases from 0.17 to 0.47 point on a scale of $0-100$; when a new symptom appears, QoL decreases 0.57 to 1.63 points. Despite the small size of these effects, two factors suggest that the scores, though numerically small, are not negligible. First, the average HD patient has a burden of 10 symptoms that lowers overall QoL on average by an amount between 14.6 points (based on mean severity of 3.1 per symptom) or 17.6 points (based on symptom prevalence) relative to a person with no symptoms. Second, studies ${ }^{[26,61-64]}$ suggest that decreased QoL is 
closely related to patient mortality. Consequently, systematic evaluation of the symptom experience of HD patients seems necessary in order to develop specific interventions aimed at reducing symptom frequency and severity. ${ }^{[24]}$ Finally, as suggested by Almutary et al., ${ }^{[8]}$ studies of QoL among HD patients should systematically include a measure of symptom burden.

Our study presents certain limitations. First, the French version of the DSI was used here for the first time. Despite a positive preliminary validation, further testing seems necessary in this regard. Second, patient symptom experience was measured only in terms of prevalence and severity. Other dimensions might be considered in future, such as distress level and frequency, ${ }^{[8]}$ including in combination with prevalence and severity. ${ }^{[10]}$ Third, symptom experience is a longitudinal dimension and may be subject to non-linear or lagged effects. ${ }^{[65]}$ Consequently, a cross-sectional study such as ours might misrepresent the condition of patients owing to the absence of time-sensitive measures. Fourth, depression was not investigated in our study. Previous studies ${ }^{[7,66-68]}$ have demonstrated the influence of depression on symptom experience, particularly regarding psychological symptoms. Fifth, patients not fluent in French were excluded from our sample. Though linguistic and, by extension, cultural homogeneity facilitated the international comparison, this remains a serious limitation of our study, given that Switzerland has four official languages and a foreign contingent that constitutes one-quarter of the total population $(24.9 \%$ in 2016 , according to the Swiss Federal Statistical Office). Hence, the generalizability of our findings is limited.

\section{Conclusions}

HD patients in Switzerland report a high number of symptoms often of moderate severity. Comparing our results with international studies revealed that symptom prevalence and severity vary widely across national contexts and seem to be linked to cultural, linguistic and organizational factors. Psychological and sex-related symptoms, in particular, need to be further explored to uncover the causes behind the observed variability. More generally, each symptom deserves greater attention given that an increment in symptom presence or severity has a negative impact on patient QoL. Even if individual symptoms have only a moderate impact, their combined effect can have severe repercussions on QoL. Consequently, it is imperative that the healthcare professionals working with this population systematically evaluate the symptoms of HD patients in order to propose tailored interventions aimed at reducing symptom frequency and severity and, ultimately, at supporting the QoL of this vulnerable population.

\section{ACKNOWLEDGEMENTS}

This study was made possible by a ReSar (recherche en santé, réadaptation et réinsertion) grant awarded to Delmas and Cohen in April 2012. Moreover, the authors would like to thank all patients agreeing to take part in this study, for their precious contribution. Correspondence regarding this article may be sent to Philippe Delmas, RN, PhD, full Professor, University of Applied Sciences and Arts Western Switzerland, School of Nursing, La Source, Lausanne, Switzerland.

\section{Conflicts of Interest Disclosure}

The authors declare they have no conflicts of interest.

\section{REFERENCES}

[1] WHO. Global status report on noncommunicable diseases 2014: attaining the nine global noncommunicable diseases targets; a shared responsibility. Geneva: World Health Organization; 2014.

[2] Lozano R, Naghavi M, Foreman K, et al. Global and regional mortality from 235 causes of death for 20 age groups in 1990 and 2010: a systematic analysis for the Global Burden of Disease Study 2010. The Lancet. 2012; 380(9859): 2095-128. https : //doi.org/10.1016/S0140-6736(12)61728-0

[3] Wetmore JB, Collins AJ. Global challenges posed by the growth of end-stage renal disease. Renal Replacement Therapy. 2016; 2(1). https://doi.org/10.1186/s41100-016-0021-7

[4] United States Renal Data System. Introduction to Volume 2: ESRD in the United States. 2016 USRDS annual data report. 2: Ann Arbor, MI : USRDS Coordinating Center; 2016.

[5] Golshayan D, Paccaud F, Wauters JP. Epidemiology of end-stage renal failure: Comparison between 2 Swiss cantons. Nephrologie. 2002; 23: 179-84. PMid: 12125324.
[6] Khan MA. Frequency of symptomatology in patients on hemodialysis: a single center experience. Rawal Medical Journal. 2012; 37(1): 24-7.

[7] Abdel-Kader K, Unruh ML, Weisbord SD. Symptom burden, depression, and quality of life in chronic and end-stage kidney disease. Clin J Am Soc Nephrol. 2009; 4(6): 1057-64. https ://doi .org/10.2 215/CJN.00430109

[8] Almutary H, Bonner A, Douglas C. Symptom burden in chronic kidney disease: a review of recent literature. Journal of Renal Care. 2013; 39(3): 140-50. https://doi.org/10.1111/j.1755-668 $6.2013 .12022 . \mathrm{x}$

[9] Caplin B, Kumar S, Davenport A. Patients' perspective of haemodialysis-associated symptoms. Nephrol Dial Transpl. 2011; 26(8): 2656-63. https : //doi.org/10.1093/ndt/gfq763

[10] Danquah FVN, Meininger J, Zimmerman L, et al. Frequency, Severity, and Distress Of Dialysis-Related Symptoms Reported by Patients on Hemodialysis. Nephrol Nurs J. 2010; 37(6): 627-39. 
[11] Davison SN, Jhangri GS. Impact of pain and symptom burden on the health-related quality of life of hemodialysis patients. Journal of Pain and Symptom Management. 2010; 39(3): 477-85. https: //doi.org/10.1016/j.jpainsymman.2009.08.008

[12] Meredith DJ, Pugh CW, Sutherland S, et al. The relationship between symptoms and blood pressure during maintenance hemodialysis. Hemodialysis Internationa. 2015; 19(4): 543-52. https ://doi . org/10.1111/hdi.12306

[13] Murphy EL, Murtagh FEM, Carey I, et al. Understanding Symptoms in Patients with Advanced Chronic Kidney Disease Managed without Dialysis: Use of a Short Patient-Completed Assessment Tool. Nephron Clinical Practice. 2009; 111(1): C74-C80.

[14] Murtagh FE, Addington-Hall J, Edmonds P, et al. Symptoms in the Month Before Death for Stage 5 Chronic Kidney Disease Patients Managed Without Dialysis. Journal of Pain and Symptom Management. 2010; 40(3): 342-52.

[15] Afshar M, Rebollo-Mesa I, Murphy E, et al. Symptom Burden and Associated Factors in Renal Transplant Patients in the U.K. Journal of Pain and Symptom Management. 2012; 44(2): 229-38.

[16] Raj R, Ahuja KD, Frandsen M, et al. Symptoms and their recognition in adult haemodialysis patients: interactions with quality of life. Nephrology (Carlton, Vic). 2016. https : //doi .org/10.1111/ne p. 12754

[17] Son YJ, Choi KS, Park YR, et al. Depression, symptoms and the quality of life in patients on hemodialysis for end-stage renal disease. American Journal of Nephrology. 2009; 29(1): 36-42. https://doi.org/10.1159/000150599

[18] Yong DSP, Kwok AOL, Wong DML, et al. Symptom burden and quality of life in end-stage renal disease: a study of 179 patients on dialysis and palliative care. Palliative Medicine. 2009; 23(2): 111-9.

[19] Figueiredo AE, Goodlad C, Clemenger M, et al. Evaluation of physical symptoms in patients on peritoneal dialysis. Int J Nephrol. 2012; 2012: 305424. https://doi.org/10.1155/2012/305424

[20] McClellan WM, Abramson J, Newsome B, et al. Physical and psychological burden of chronic kidney disease among older adults. Am J Nephrol. 2010; 31(4): 309-17. https ://doi .org/10.1159/00 0285113

[21] Noble H, Meyer J, Bridges J, et al. Exploring symptoms in patients managed without dialysis: a qualitative research study. Journal of Renal Care. 2010; 36(1): 9-15. PMid: 20214703. https: //doi.org/10.1111/j.1755-6686.2010.00140.x

[22] Yu IC, Huang JY, Tsai YF. Symptom cluster among hemodialysis patients in Taiwan. Appl Nurs Res. 2012; 25(3): 190-6. PMid: 21273045. https://doi.org/10.1016/j.apnr.2010.11.002

[23] Weisbord SD. Symptoms and their correlates in chronic kidney disease. Adv Chronic Kidney D. 2007; 14(4): 319-27. PMid: 17904498. https://doi.org/10.1053/j.ackd.2007.07.004

[24] Humphreys J, Lee KA, Carrieri-Kohlman V, et al. Theory of Symptom Management. In: Smith M.J., P.R. L, editors. Middle Range Theory for Nursing. New York: Springer Publishing Company; 2008. $145-58 \mathrm{p}$.

[25] Tsai YC, Hung CC, Hwang SJ, et al. Quality of life predicts risks of end-stage renal disease and mortality in patients with chronic kidney disease. Nephrol Dial Transpl. 2010; 25(5): 1621-6.

[26] Weisbord SD, Bossola M, Fried LF, et al. Cultural comparison of symptoms in patients on maintenance hemodialysis. Hemodial Int. 2008; 12(4): 434-40. https://doi.org/10.1111/j.1542-475 $8.2008 .00307 . \mathrm{x}$

[27] Grove SK, Burns N, Gray J. The Practice of Nursing Research: Appraisal, Synthesis, and Generation of Evidence (7 ed.). Chine: Elsevier/Saunders; 2012.
[28] Boini S, Bloch J, Briançon S. Surveillance de la qualité de vie des sujets atteints d'insuffisance rénale chronique terminale [Surveillance on the quality of life of people with end-stage chronic kidney disease] Institut de veille sanitaire. 2008.

[29] Delmas P, O'Reilly L, Iglesias K, et al. Feasibility, Acceptability, and Preliminary Effects of Educational Intervention to Strengthen Humanistic Practice Among Hemodialysis Nurses in the Canton of Vaud, Switzerland: A Pilot Study. International Journal for Human Caring. 2016; 20(1): 31-43. https://doi.org/10.20467/109 1-5710-20.1.31

[30] Weisbord SD, Fried LF, Arnold RM, et al. Development of a symptom assessment instrument for chronic hemodialysis patients: the dialysis symptom index. Journal of Pain and Symptom Management 2004; 27(3): 226-40. https://doi.org/10.1016/j.jpainsym man.2003.07.004

[31] Weisbord SD, Fried LF, Arnold RM, et al. Prevalence, severity, and importance of physical and emotional symptoms in chronic hemodialysis patients. J Am Soc Nephrol. 2005; 16(8): 2487-94. https://doi.org/10.1681/ASN. 2005020157

[32] Weisbord SD, Fried LF, Mor MK, et al. Renal provider recognition of symptoms in patients on maintenance hemodialysis. Clin J Am Soc Nephro. 2007; 2(5): 960-7.

[33] Vallerand RJ. Vers une méthodologie de validation trans-culturelle de questionnaires psychologiques: Implications pour la recherche en langue française. Canadian Psychology/Psychologie Canadienne. 1989; 30(4): 662-80. https://doi .org/10.1037/h0079856

[34] Sim J, Wright CC. The Kappa Statistic in Reliability Studies: Use, Interpretation, and Sample Size Requirements. Physical Therapy. 2005; 85(3): 257-68. PMid: 15733050.

[35] Streiner DL, Norman GR. Health measurement scales: a practical guide to their development and use. New York: Oxford University Press; 2008. https://doi .org/10.1093/acprof : oso/978019 9231881.001 .0001

[36] Leplege A, Reveillere C, Ecosse E, et al. Psychometric properties of a new instrument for evaluating quality of life, the WHOQOL-26, in a population of patients with neuromuscular diseases. L'Encephale. 2000; 26(5): 13-22. PMid:11192800.

[37] World Health Organization Quality of Life Group. The World Health Organization Quality of Life Assessment (WHOQOL): Development and general psychometric properties. Social Science and Medicine. 1998(46): 1569-85. PMid: 9672396.

[38] Swiss Federal Statistical Office. Situation économique et sociale de la population [Economic and social situation of the population] Panorama: Swiss Federal Statistical Office; 2017.

[39] Bondy SJ, Rehm J, Walsh G, et al. Low-risk Drinking Guidelines: The Scientific Evidence. Revue Canadienne de santé publique. 1997; 90(4): 264-70.

[40] Abel T, Hofmann K, Schori D. Social and regional variations in health status and health behaviours among Swiss young adults. Swiss Med Wkly. 2013; 143: w13901. https://doi.org/10.4414/sm w. 2013.13901

[41] Theofilou P. Association of insomnia symptoms with kidney disease quality of life reported by patients on maintenance dialysis. Psychol Health Med. 2013; 18(1): 70-8.

[42] Claxton RN, Blackhall L, Weisbord SD, et al. Undertreatment of symptoms in patients on maintenance hemodialysis. Journal of Pain and Symptom Management. 2010; 39(2): 211-8. https: //doi.org/10.1016/j.jpainsymman.2009.07.003

[43] Abdel-Hady M, Bansal S, Davison SM, et al. Treatment of chronic viral hepatitis $\mathrm{C}$ in children and adolescents: UK experience. Archives of Disease in Childhood. 2014; 99(6): 505-10. PMid: 24492797. https://doi.org/10.1136/archdischild-2013-304601 
[44] Feldman R, Berman N, Reid MC, et al. Improving symptom management in hemodialysis patients: identifying barriers and future directions. J Palliat Med. 2013; 16(12): 1528-33. https : //doi.or g/10.1089/jpm.2013.0176

[45] El-Assmy A. Erectile dysfunction in hemodialysis: A systematic review. World Journal of Nephrol. 2012; 1(6): 160-5. https : //doi.org/10.5527/wjn.v1.i6.160

[46] Stewart M. Narrative Literature Review: Sexual Dysfunction in the Patient on Hemodialysis. Nephrology Nursing Journal. 2006; 33(6) PMid: 17219725.

[47] Fernandes GV, dos Santos RR, Soares W, et al. The impact of erectile dysfunction on the quality of life of men undergoing hemodialysis and its association with depression. The Journal of Sexual Medicine. 2010; 7(12): 4003-10. https ://doi .org/10.1111/j.1743-610 9.2010.01993.x

[48] Mor MK, Sevick MA, Shields AM, et al. Sexual function, activity, and satisfaction among women receiving maintenance hemodialysis. Clin J Am Soc Nephro. 2014; 9(1): 128-34. https ://doi.org/10 .2215/CJN. 05470513

[49] Coelho-Marques FZ, Wagner MB, de Figueiredo CEP, et al. Quality of life and sexuality in chronic dialysis female patients. Int J Impot Res. 2006; 18(6): 539-43.

[50] Weisbord SD. Female Sexual Dysfunction in ESRD: An Underappreciated Epidemic? Clin J Am Soc Nephro. 2012; 7(6): 881-3.

[51] Mapes DL, Lopes AA, Satayathum S, et al. Health-related quality of life as a predictor of mortality and hospitalization: the Dialysis Outcomes and Practice Patterns Study (DOPPS). Kidney International. 2003; 64(1): 339-49. https://doi.org/10.1046/j.1523-175 $5.2003 .00072 . x$

[52] Fukuhara S, Lopes AA, Bragg-Gresham JL, et al. Health-related quality of life among dialysis patients on three continents: the Dialysis Outcomes and Practice Patterns Study. Kidney International. 2003; 64(5): 1903-10. https://doi.org/10.1046/j.1523-1755.20 $03.00289 . \mathrm{x}$

[53] Eicher M, Delmas P, Cohen C, et al. Version Française de la Théorie de Gestion des Symptômes (TGS) et son application. Recherche En Soins Infirmiers. 2013; 112(1): 14. https ://doi.org/10.3917/ rsi.112.0014

[54] Berger PL, Luckmann T. The Social Construction of Reality. New York City (NY), USA: Anchor Books; 1966.

[55] Conrad P, Barker KK. The Social Construction of Illness: Key Insights and Policy Implications. Journal of Health and Social Behavior. 2010; 51(S): 67-79.

[56] Spector RE. Cultural Diversity in Health and Illness. London: Pearson Education; 2013.

[57] Rothgang H, Cacace M, Grimmeisen S, et al. The changing role of the State in Healthcare systems. European Review. 2005; 13(1): 187-212. https://doi.org/10.1017/S1062798705000256
[58] Bohm K, Schmid A, Gotze R, et al. Five types of OECD healthcare systems: empirical results of a deductive classification. Health Policy. 2013; 113(3): 258-69. https://doi.org/10.1016/j .healthpo 1.2013.09.003

[59] OECD. Health expenditure and financing: Organisation for Economic Co-operation and Development (OECD); 2017 [cited 2017 12.07.2017]. Available from: http://stats.oecd.org/Index.a spx?DataSetCode=SHA

[60] Birmele B, Le Gall A, Sautenet B, et al. Clinical, sociodemographic, and psychological correlates of health-related quality of life in chronic hemodialysis patients. Psychosomatics. 2012; 53(1): 30-7. https://doi.org/10.1016/j.psym.2011.07.002

[61] Ferreira RC, da Silva Filho CR. Quality of life of chronic renal patients on hemodialysis in Marilia, SP, Brazil. Jornal brasileiro de nefrologia: 'orgao oficial de Sociedades Brasileira e LatinoAmericana de Nefrologia. 2011; 33(2): 129-35. PMid: 21789425. https : //doi.org/10.1590/S0101-28002011000200003

[62] Hedayati SS, Bosworth HB, Briley LP, et al. Death or hospitalization of patients on chronic hemodialysis is associated with a physicianbased diagnosis of depression. Kidney International. 2008; 74(7): 930-6.

[63] Hedayati SS, Jiang W, O'Connor CM, et al. The association between depression and chronic kidney disease and mortality among patients hospitalized with congestive heart failure. American Journal of Kidney Diseases. 2004; 44(2): 207-15.

[64] Kimmel PL. Psychosocial factors in adult end-stage renal disease patients treated with hemodialysis: correlates and outcomes. American Journal of Kidney Diseases: the Official Journal of the National Kidney Foundation. 2000; 35(4 Suppl 1): S132-40. https : //doi.org/10.1016/S0272-6386(00)70240-X

[65] Weisbord SD, Mor MK, Sevick MA, et al. Associations of depressive symptoms and pain with dialysis adherence, health resource utilization, and mortality in patients receiving chronic hemodialysis. Clin J Am Soc Nephrol. 2014; 9(9): 1594-602. https : //doi .org/10.2 215/CJN.00220114

[66] Gamondi C, Galli N, Schonholzer C, et al. Frequency and severity of pain and symptom distress among patients with chronic kidney disease receiving dialysis. Swiss medical weekly. 2013; 143: w13750. https ://doi.org/10.4414/smw.2013.13750

[67] Chilcot J, Wellsted D, Vilar E, et al. An association between residual renal function and depression symptoms in haemodialysis patients. Nephron Clinical Practice. 2009; 113(2): c117-24. https : //doi.org/10.1159/000229019

[68] Turkmen K, Yazici R, Solak Y, cet al. Health-related quality of life, sleep quality, and depression in peritoneal dialysis and hemodialysis patients. Hemodialysis international International Symposium on Home Hemodialysis. 2012; 16(2): 198-206. 